\title{
Alloy Gold Deposits for Electronic Applications
}

\author{
AN EVALUATION OF THE GOLD-COPPER-CADMIUM \\ SULPHITE SYSTEM
}

\author{
W. A. Fairweather \\ Imasa Silvercrown, Slough, Buckinghamshire, England
}

\begin{abstract}
Although processes for the electrodeposition of alloy golds have been available for some years they have so far found few applications in the electronics industry. This article, based in part on a paper presented to the Ninth World Congress on Metal Finishing held in Amsterdam in October, first reviews the literature on the numerous alloy gold systems available and then gives an assessment of the particular process considered by the author to be the most satisfactory.
\end{abstract}

One of the obvious ways of economising in the use of gold in the electronics industry lies in its alloying with one or more base metals. The widely used acid types of hard gold deposits contain only 0.2 to 0.5 per cent of nickel or cobalt, and the question one has to ask is: "How far can we dilute gold before we begin to lose its desirable properties ?"

The use of alloyed gold has attractions in that gold can be saved without a reduction in the thickness of deposits with the consequent risk of porosity, while, as an alternative to selective plating, it means that some saving can be effected while retaining an "all over" deposit, so avoiding the risk of corrosion products spreading from the non-critical areas. The dilution of gold with a base metal of lower density also offers a dual advantage in not only saving a certain percentage of gold weight for weight, but also in a reduction in density of the alloy deposited.

Alloyed gold deposits have been used for many years in the decorative field but generally to secure a particularly attractive colour. The gold was alloyed with one, two or more of a considerable range of metals. These deposits were, however, extremely thin, while control of the electrolyte was very important as the colour produced tended to change with time.

All these earlier alloy processes were based on the alkaline or neutral cyanide bath, but in more recent years proprietory acid cyanide processes have become available, while sulphite electrolytes were introduced in the late 1960s. But although plating technology has been capable of producing alloy gold deposits for some considerable time, it was the rising price of gold in the years 1973 to 1975 that caused their use in electronic applications to be evaluated, and during that period a number of papers appeared on this subject (1-6). Despite this flow of information, however, there has been but little use of alloyed golds in the electronics industry. A review of the current processes and of the information available on them will indicate some of the reasons for this lack of enthusiasm by the industry.

The most successful alkaline cyanide processes are based upon alloying additions of either silver or of copper and cadmium. A very wide range of alloy deposits, from 90 down to 50 per cent gold, can be obtained from the silver-gold alloy processes, but they have poor resistance to tarnish and corrosion. Also they can become heavily filmed and poor in colour due to cyanide breakdown and polymer formation, which further cause brittleness. This can be overcome to some extent by carbon treatment.

The gold-copper-cadmium deposits are somewhat difficult to control as the cadmium content of the solution has to be very low owing to the poor stability of the cadmium cyanide complex and to the low deposition potential of cadmium. Also, with an alkaline electrolyte containing free cyanide, there is the problem of increasing carbonate concentration so that the bath has a finite life.

Gold-copper deposits can be obtained from a neutral cyanide solution, and it is possible to control the alloy composition from the neutral process more readily than from a high cyanide process, while there is less free copper in the deposit with the neutral electrolyte. With acid electrolytes it is somewhat 
difficult to achieve a high base metal content, the maximum being of the order of 10 per cent. With the gold-copper alloys it is possible to have deposits with free copper present, and true alloys can be obtained only by heat treatment.

Alloy deposits can also be obtained successfully from sulphite electrolytes, the alloying elements being generally the same as those used in the cyanide electrolytes. The most successful alloys in the sulphite electrolyte have been those with copper and cadmium, possibly with a trace of arsenic.

In our experience the gold-copper-cadmium system gives the most satisfactory deposits, and alloys in the 75 to 80 per cent gold region are uniform in colour, fairly ductile, not excessively stressed, and have good resistance to corrosion. From our own tests, and from reviewing the results of others, we agree with Mason and his collaborators (3) that alloy deposits of this type give the most satisfactory results from the point of view of satisfying the demands of the electronics industry. But while Mason found the results with the gold-copper-cadmium deposits were probably the best, he and his co-workers were not enthusiastic about the cyanide electrolyte, which was very difficult to control. In our opinion the sulphite electrolyte is easier to control, although any process involving two alloying elements will naturally need more control than a simple process.

\section{Review of Alloy Processes}

However, before discussing a specific process it is worth while reviewing all the alloys available and the results obtained with them so far in terms of corrosion resistance and contact resistance to see to what extent the deposits may satisfy the requirements of the electronics industry. Table I summarises the results presented by the various authors already quoted. Values for pure gold (99.9 per cent) are included for comparison, these deposits being of course soft, with low stress and good resistance to corrosion.

\section{Gold-Copper Alloys}

Quite a number of these alloys have been reported. Their hardness values are all fairly high, in the range 250 to $400 \mathrm{VPN}$. The assessment of resistance to wear depends to some extent on the method employed, but in general it is fairly good, presumably on account of the high hardness. Stress is not excessive, contact resistance is reasonably good, but corrosion resistance shows variable results. Contact resistance after four months at $70^{\circ} \mathrm{C}$ and 26 months at room temperature did not show an unacceptable rise in the case of the alloy investigated by Foulke and Duva (1). The sulphite deposits studied by Souter (4) are, however, reported as having poor resistance to corrosion.

\section{Gold-Copper-Cadmium Alloys}

All these deposits, whether from cyanide or sulphite electrolytes, show reasonable ductility and have hardnesses in the range 200 to $450 \mathrm{VPN}$, appreciably higher values than those obtained with hard acid gold deposits. All the results of wear testing are quite good. In the case of the deposits associated with Flühmann (5) the lower figures in brackets are those obtained after a "wearing in" of the contacts, these deposits exhibiting high hardness, good conductivity and acceptable resistance to corrosion. As regards stress in the deposits, Foulke and Duva (1) report an unusual compressive stress for the sulphite deposits. Contact resistance values are generally acceptable, although Foulke and Duva report increasing contact resistance after 250 hours at $100^{\circ} \mathrm{C}$ on copper substrates, presumably because of copper diffusion; the same test on a nickel substrate gave satisfactory results.

\section{Gold-Silver Alloys}

The hardness figures for gold-silver alloy deposits are again on the high side, from 180 to 290 VPN. Wear resistance is good in one case, but Souter (4) comments that the deposits gall. Ductility is poor, contact resistance reasonable, and corrosion resistance shows considerable variation; in our own experience it is poor. Contact resistance after four months at $70^{\circ} \mathrm{C}$ is beginning to increase.

\section{Gold-Cadmium Alloys}

Hardnesses range from 250 to 320 VPN, ductility is good, but stresses are high in two cases, while another unusual compressive stress is reported by Foulke and Duva (1). Contact resistance is initially good, but after four months is beginning to increase, while after 26 months at room temperature it has become excessive.

\section{Gold-Cobalt and Gold-Nickel}

The first two sets of figures are for the more conventional acid bright gold deposits, included as a reference. Deposit hardness is in the more acceptable range, 110 to $180 \mathrm{VPN}$, wear resistance is good, stress somewhat on the high side, ductility rather low, and corrosion resistance quite good. Contact resistance after 250 hours at temperature was found not to be excessively high.

The deposits with a relatively high nickel content, obtained from cyanide electrolytes, are very hard, 350 to $420 \mathrm{VPN}$, but wear resistance is poor. Although it was reported that deposits were cracked due to their very poor ductility, stresses were not found to be exceptionally high. Contact resistance was poor initially, and corrosion resistance became poor with long periods of exposure. 
Table I

Summary of Data on Alloy Gold Electrodeposits

\begin{tabular}{|c|c|c|c|c|c|c|c|c|c|c|c|}
\hline \multirow[b]{2}{*}{$\begin{array}{c}\text { Refer- } \\
\text { ence }\end{array}$} & \multirow{2}{*}{\multicolumn{3}{|c|}{ Alloy }} & \multirow[b]{2}{*}{$\begin{array}{l}\text { Hardness } \\
\text { VPN }\end{array}$} & \multirow[b]{2}{*}{$\begin{array}{l}\text { Wear } \\
\text { Resist- } \\
\text { ance }\end{array}$} & \multirow[b]{2}{*}{$\begin{array}{l}\text { Stress } \\
\text { p.s.i. }\end{array}$} & \multirow[b]{2}{*}{ Ductility } & \multirow[b]{2}{*}{$\begin{array}{l}\text { Corrosion } \\
\text { Resistance }\end{array}$} & \multicolumn{3}{|c|}{ Contact Resistance in Milliohms } \\
\hline & & & & & & & & & Initial & $\begin{array}{l}\text { After } 4 \\
\text { Months } \\
\text { at } 70^{\circ} \mathrm{C}\end{array}$ & $\begin{array}{c}\text { After } 26 \\
\text { Months } \\
\text { at Room } \\
\text { Temperature }\end{array}$ \\
\hline 3 & \multicolumn{3}{|c|}{ Au (99.9 pure) } & $60-80$ & & 1400 & & Very good & & & \\
\hline 3 & $\begin{array}{l}\mathrm{Au} \\
66\end{array}$ & $\begin{array}{l}\mathrm{Cu} \\
34\end{array}$ & & $300-350$ & $\begin{array}{l}\text { Very } \\
\text { good }\end{array}$ & 13000 & & Poor & & & \\
\hline 1 & 75 & 25 & (Neutral) & 300 & & 4000 & & Fair & 0.4 & & 3.5 \\
\hline $\begin{array}{l}1 \\
1\end{array}$ & $\begin{array}{l}80 \\
75\end{array}$ & $\begin{array}{l}20 \\
25\end{array}$ & $\begin{array}{l}\text { (Acid) } \\
\text { (Sulphite) }\end{array}$ & 250 & & 2000 & & Good & 0.4 & 2.7 & 0.4 \\
\hline 4 & 66 & 34 & (Sulphite) & $290-400$ & Fair & & & & & & \\
\hline 3 & $\begin{array}{l}\mathrm{Au} \\
80\end{array}$ & $\begin{array}{l}\mathrm{Cu} \\
19\end{array}$ & $\begin{array}{c}\mathrm{Sb} \\
1\end{array}$ & $320-370$ & Fair & & & Poor & & & \\
\hline 5 & $\begin{array}{l}\mathrm{Au} \\
75\end{array}$ & $\begin{array}{l}\mathrm{Cu} \\
22\end{array}$ & $\begin{array}{c}\mathrm{Cd} \\
3\end{array}$ & $380-450$ & & & $5 \%$ & & $3-5(2-3)$ & & \\
\hline 1 & 75 & 14 & 11 (Cyanide) & $380-420$ & Excellent & & & Good & & & \\
\hline 2 & 75 & 18 & 7 (Cyanide) & 385 & Slight & & $2 \%$ & & 1.0 & & \\
\hline 1 & 76 & & (Sulphite) & $204-287$ & & -18000 & & & 1.0 & & \\
\hline 3 & $\begin{array}{l}\mathrm{Au} \\
75\end{array}$ & $\begin{array}{l}\mathrm{Ag} \\
25\end{array}$ & & $270-290$ & Good & & & Poor & & & \\
\hline $\begin{array}{l}1 \\
4\end{array}$ & 75 & 25 & & $150-190$ & Poor & 8000 & Poor & Good & 0.7 & 4.8 & 2.9 \\
\hline & 66 & 34 & & $180-190$ & $\begin{array}{l}\text { Poor } \\
\text { (Gall) }\end{array}$ & & & & & & \\
\hline 3 & $\begin{array}{l}\mathrm{Au} \\
90\end{array}$ & $\begin{array}{l}\mathrm{Cd} \\
10\end{array}$ & & $300-320$ & & 25000 & & Poor & & & \\
\hline $\begin{array}{l}1 \\
1\end{array}$ & $\begin{array}{l}75 \\
90\end{array}$ & $\begin{array}{l}25 \\
10\end{array}$ & & 250 & & $\begin{array}{l}-18000 \\
<20000\end{array}$ & Good & Good & 0.6 & 6.9 & 43 \\
\hline & $\mathrm{Au}$ & Co & $\mathrm{Ni}$ & & & & & & & & \\
\hline $\begin{array}{l}3 \\
2\end{array}$ & $\begin{array}{l}99.7 \\
99.8\end{array}$ & $\begin{array}{l}0.2 \\
0.2\end{array}$ & & $\begin{array}{l}110-150 \\
175-180\end{array}$ & $\begin{array}{l}\text { Good } \\
\text { Slight }\end{array}$ & 20000 & $<0.4 \%$ & Very good & 0.7 & & \\
\hline 1 & 80 & & 20 (Cyanide) & 350 & -190 & -1000 & $\begin{array}{l}\text { Very } \\
\text { poor }\end{array}$ & Poor & 2.0 & 2.8 & 15 \\
\hline 4 & 83 & & 17 & $390-420$ & $\begin{array}{l}\text { Poor } \\
\text { (crack) }\end{array}$ & & & $\begin{array}{l}\text { Poor } \\
\text { (crack) }\end{array}$ & & & \\
\hline 1 & $\begin{array}{l}\mathrm{Au} \\
80\end{array}$ & $\begin{array}{l}\mathrm{Pd} \\
20\end{array}$ & (Sulphite) & 185 & & & Good & Good & 3.0 & 4.0 & \\
\hline 4 & $\begin{array}{l}\mathrm{Au} \\
92\end{array}$ & $\mathrm{Cu}$ & $\begin{array}{l}\text { Pd } \\
\text { (Sulphite) }\end{array}$ & $280-310$ & Fair & & & & & & \\
\hline 1 & $\begin{array}{l}\mathrm{Au} \\
75\end{array}$ & $\begin{array}{l}\mathrm{Sn} \\
25\end{array}$ & & 200 & & 4000 & Good & Good & 1.2 & 2.5 & \\
\hline
\end{tabular}

\section{Gold-Palladium and Gold-Copper-Palladium}

These deposits gave, on the whole, quite good results, but the inclusion of palladium in the alloys does not of course offer much advantage in terms of cost saving.

\section{Gold-Tin}

This alloy deposit, reported by Foulke and Duva, appears to be quite good with reasonable hardness and ductility. Stress is not excessively high and con- tact resistance is satisfactory, but the deposition process is difficult to control as the tin is present in the stannous form which tends to oxidise.

\section{Evaluation of a Gold-Copper-Cadmium Sulphite System}

After this survey of the literature and with some previous experience of alloy gold systems, we selected the gold-copper-cadmium sulphite system, with 75 per cent gold, as having the most satisfactory deposit 
Table II

Screening Test on Gold-Copper-Cadmium Alloy

\begin{tabular}{c|c|c}
\hline & \multicolumn{2}{|c}{$\begin{array}{c}\text { Contact Resistance, } \\
\text { milliohms }\end{array}$} \\
\cline { 2 - 3 } Alloy & Initial & $\begin{array}{c}\text { After 24 Hours } \\
\text { Gas Test }\end{array}$ \\
\hline A 75Au 15Cu 10Cd & 9.1 & 10.7 \\
B 75Au 22Cu 3Cd & 7.2 & 15.4 \\
C 75Au 10Cu 15Cd & 7.8 & 9.4
\end{tabular}

characteristics. This was investigated in the laboratory, but the major part of the evaluation was carried out by connector manufacturers. Because of a slight increase in contact resistance observed after gas testing the deposits, duplex deposits consisting of 4 microns of the alloy gold overplated with 1 micron pure gold were also tested.

\section{Contact Resistance}

Contact resistance measurements were made on commercial phosphor-bronze printed circuit connectors plated to 5 microns with gold-copper-cadmium alloys of different compositions. The classical crossed rods technique measures the constriction resistance across two contacting surfaces. The figures quoted for actual connectors include a significant contribution from the bulk resistance of the connector, that is the intrinsic resistivity of the phosphor bronze or beryllium copper from which they are manufactured.

After determining the initial contact resistance, the connectors were subjected, unmated, to the 24 hour gas test as specified in the UK. Defence Standard DTD 938. The connectors were then re-mated and contact resistance remeasured. The results are shown in Table II. They show that the high copper alloy (B) gives an unacceptably high increase in contact resistance after gas testing. The connector surfaces were noticeably discoloured. Alloys A and C, while showing only slight increases in contact resistance (no surface film was apparent in either case) could be differentiated in that Alloy $\mathrm{C}$, with a high cadmium content, showed greater porosity on the edges of the connectors. Alloy A, 75 per cent gold, 15 per cent copper and 10 per cent cadmium, was therefore selected for all future work.

\section{Solderability}

It has been claimed that gold-copper-cadmium alloys are not easily solderable after ageing of the deposit (6). Solderability tests were carried out on 2.5 micron deposits and cobalt-hardened deposits from an acid cyanide bath.

Initial solderability was good in each case when tested at $240^{\circ} \mathrm{C}$ using a non-activated rosin flux, with good wetting being obtained with 1 to 2 seconds immersion.

Test pieces were then subjected to steam ageing for 16 hours and 24 hours at $93^{\circ} \mathrm{C}$, and re-tested. The acid hard gold deposits showed no deterioration in solderability but the alloy deposits required 3 seconds immersion before good wetting was obtained after 16 hours ageing, while non-wetting occurred with 5 seconds immersion after the 24 hour ageing. More detailed work is continuing on this characteristic.

\section{Wear Resistance}

Wear resistance tests were carried out by an independent testing body using a rider/flat apparatus. Combinations of gold deposits were tested using a $6 \mathrm{~cm}$ traverse, at 10 traverses a minute, to 500 cycles. The results are summarised in Table III.

It has been established over the last few years that pure gold deposits from sulphite electrolytes and from organically hardened cyanide electrolytes will show poor wear resistance when mated against themselves.

Table III

Wear Tests on Alloy Gold and Pure Gold Deposits

\begin{tabular}{c|l|l|l}
\hline \multicolumn{1}{c|}{ Rest } & \multicolumn{1}{|c|}{ Rider } & \multicolumn{1}{|c}{ Flat } & Wear Characteristics \\
\cline { 2 - 4 } 1 & Alloy gold, sulphite & Alloy gold, sulphite & \multicolumn{1}{|c}{ Excellent } \\
2 & Alloy gold, sulphite & Acid hard gold & Excellent \\
3 & Acid hard gold & Alloy gold, sulphite & Excellent \\
4 & Alloy gold, sulphite & Pure gold, sulphite & Very poor \\
5 & Pure gold, sulphite & Alloy gold, sulphite & Satisfactory \\
6 & Alloy gold, sulphite & Pure gold, cyanide, organic & Very poor \\
7 & Pure gold, cyanide, organic & Alloy gold, sulphite & Satisfactory
\end{tabular}


Table IV

Contact Resistance on Copper Rods Plated 5 microns Gold-Copper-Cadmium Alloy

\begin{tabular}{c|c|c|c|c}
\hline & \multicolumn{3}{|c}{ Contact Resistance, milliohms } \\
\cline { 2 - 5 } Load, gm & Initial & After Ageing & After 4 Hours Gas & $\begin{array}{c}\text { After 4 Hours Gas } \\
\text { and Wear }\end{array}$ \\
\hline 75 & 7 & 2.6 & 14 & 2.6 \\
125 & 7 & 2 & 11 & 2 \\
175 & 5 & 1.9 & 9.5 & 1.9 \\
250 & 4.8 & 1.8 & 7.2 & 1.8 \\
300 & 5.2 & 1.8 & 7.3 & 1.8
\end{tabular}

Acceptable results can be obtained when these deposits are matched against pure gold deposits from the cobalt or nickel hardened acid cyanide baths. It was therefore surprising to obtain such excellent results from the 75 per cent gold sulphite system. The hardness of these deposits is in the range 320 to 350 VPN, and it would appear that their structure is quite different from that of the pure gold sulphite deposits, although no detailed work has been done in this respect.

The high hardness of the deposit probably explains the very poor performance recorded in Tests 4 and 6 where the 75 per cent gold deposit was the rider. The result of Test Nos. 2 and 3 show that the alloy deposits will give satisfactory wear performance in all combinations with acid gold deposits.

\section{Connector Manufacturers' Tests}

The results obtained by six manufacturers can be summarised as follows:

Company A had carried out quite a comprehensive evaluation of alloy deposits and had already come to the conclusion that gold-silver alloys were unsuitable. The results of contact resistance measurements on alloy plated copper rods, using the cross rods technique, are given in Table IV.

Note the reduction in contact resistance after "ageing". This consists of vibrating the rods gently to simulate the mild vibrations which would normally be present in the assembled electronic device. It constitutes in fact a "bedding down" of the connector. The contact resistance increased after the 4 hour gas test, but decreased to an acceptable level after "wear" which consists of a simulated insertion and withdrawal. The slight film left after the gas test is therefore easily dislodged.

On insertion tests of both gold-copper-cadmium and duplex deposits with acid gold plated pins no significant difference in insertion force, nor any wear or galling, was noted. Increase in contact resistance was satisfactorily low in each case.

The effect of wear in 22-way edge connectors after 200 insertions with an acid gold plated mating surface, followed by the 20-day Industrial Atmosphere test to British Standard 2011, showed a rise in contact resistance that was acceptably low, from 0.7 to 1.1 milliohms. Wear resistance and freedom from porosity were satisfactory. For this particular connector, this company specify a 200 insertion/ withdrawal test. How many companies have specifications calling for 500 or more insertions when such high requirements may be unrealistic?

Company B's evaluation was slightly different from the others. Contact resistance was measured initially, then after 250 insertions with an acid gold plated circuit board, and showed an increase from 8.61 to 9.52 milliohms. No porosity was found after the 48 hour gas test. The performance of the duplex deposits was concluded to be satisfactory.

Company $\mathrm{C}$ also evaluated duplex deposits in a 40-way edge connector and included tests on exposure to damp heat and dry heat, British Defence Standard D.E.F. 500. The damp heat test was 21 days at $40^{\circ} \mathrm{C}$ and 95 per cent relative humidity. The dry heat test was 21 days at $125^{\circ} \mathrm{C}$. Both resulted in a slight rise to 8.0 from an initial 7.5 milliohms. Wear tests were carried out here by inserting and withdrawing a steel plate 500 times, but this company has since modified its test procedure and now used an acid gold plated steel plate. Again, satisfactory results were obtained from the duplex system, a contact resistance of 7.2 being recorded.

Company D evaluated a simple alloy deposit of 1.25 microns on copper plated brass pin and socket connectors. The effect of prolonged heating for 500 hours at $125^{\circ} \mathrm{C}$ was an increase in contact resistance from 3.49 to 6.37 milliohms. In this respect the coating was comparable with their present 24 carat deposits.

A British Post Office specification calls for 1,000 
hours at $80^{\circ} \mathrm{C}$ and emphasis is being placed on this now that alloy golds are being considered more seriously. Unfortunately, no figures are available for this particular test at the moment, but we are investigating the effect of prolonged exposure to $80^{\circ} \mathrm{C}$ of alloy gold deposits on copper and on nickel undercoats. However, from the results quoted the performance of these alloys at elevated temperatures would appear to be satisfactory.

Another interesting feature of this Company's evaluation was their observation of wear resistance. Pins and sockets, both alloy gold plated, were mated and unmated 500 times and no sign of galling or wear was noted.

Company E carried out a comprehensive series of tests on the compatibility of acid gold, duplex deposits and alloy sulphite deposits in a 40-way edge connector. Where alloy sulphite deposits mated with each other an increase in insertion force of approximately 50 per cent over acid gold mating surfaces was noted. However, this required force was still thought to be satisfactory. All the connectors and circuit board type edge contacts were examined carefully at $\times 40$ magnification and no appreciable differences in wear pattern were observed.

Contact resistance of the alloy deposits showed no increase after wear testing and 24 hours gas test. The fact that the previously noted increases for alloy deposits were not detected here can be explained by the test procedure. The gas test was carried out on the unmated components. The components had then to be mated before measurement of contact resistance and this probably removed any slight film left after gas testing. No film formation could be observed.

Company $\mathrm{F}$ investigated 20 -way edge connectors plated with alloy gold and with the duplex system. The 500 insertion/withdrawal test was made with an acid gold plated circuit board. Wear and contact resistance were concluded to be satisfactory. The alloy deposits showed the expected increase in contact resistance compared with the duplex deposits, around 12 milliohms compared with 5 milliohms, but this was acceptable.

\section{Discussion}

For all the work carried out by ourselves and other companies, for all the published literature on this subject, there has still been little, if any, acceptance by the electronics industry of alloy gold deposits. Before they can be accepted the industry will have to allow some relaxation or modification of existing specifications.

The increase in contact resistance after gas testing these deposits is slightly greater than for pure gold deposits, but is it unacceptable? We would say it is acceptable for a large proportion of applications.

The wear resistance and solderability of these deposits are acceptable. The effect of long term exposure to heat has not yet been established, but results in the literature suggest that this fear of copper diffusion to the surface may be exaggerated, especially when a nickel undercoat is used.

Duplex deposits using a top coat of pure gold may constitute a satisfactory compromise enabling equivalent performance to be obtained from thinner gold deposits than previously used, although the plating procedure then becomes more complex. The work of Ashurst and Neale (7) showed quite conclusively that the use of undercoats, or the use of electropolishing to improve a surface, has a significant effect on the porosity of the gold deposit applied, and proved that gold thickness could be reduced without lowering porosity standards.

Although there is a strong case for the acceptance of alloy deposits, this should not be understood as the most important way in which gold plating costs can be reduced. The use of undercoats, the use of ultrasonics during gold plating and the chemical polishing of the basis copper alloy all offer satisfactory means of reducing gold costs. The most effective single way is the use of selective plating, but such methods require elaborate jigging or expensive equipment, thus increasing capital outlay, and therefore the adoption of such techniques is generally confined to the larger manufacturers.

The existence of these alternative methods should not, however, allow alloy gold processes to be ignored. After adoption of one or other of the above mentioned methods, the use of alloy golds will allow even greater savings.

\section{Acknowledgements}

The author would like to thank Mr. E. A. Baker, Managing Director, IMASA Silvercrown, for his valuable assistance in compiling this paper. The assistance of $\mathrm{Mr}$. $M$. Ackroyd, of the Tin Research Institute, is al'so very much appreciated. Thanks are also due to the staff of the IMASA Silvercrown laboratory who contributed to the work.

\section{References}

1 G. Foulke and R. Duva, A.E.S. Fourth Plating in the Electronics Industry Symposium, 1973

2 F. I. Nobel, D. W. Thomson and J. M. Leibel, A.E.S. Fourth Plating in the Electronics Industry Symposium, 1973; Plating, 1973, 60, (7), 720

3 D. R. Mason, A. Blair and P. Wilkinson, Proceedings, Internepcon 1974, Connector Symposium, pp 48-61; Trans. Inst. Metal Finish., 1974, 52, 143. See also D. R. Mason, Gold Bull., 1974, 7, (4), 104

$4 \mathrm{~J}$. Souter, Proceedings, Internepcon 1974, Connector Symposium, pp 62-76

5 W. Flühmann, W. Saxer, F. Aubert and H. E. Hintermann, Galvanotechnik, 1974, 65, (8), 652

$6 \mathrm{H}$. Shoushanian and A. M. Weisberg, A.E.S. Fifth Plating in the Electronics Industry Symposium, 1975

7 K. G. Ashurst and R. W. Neale, Trans. Inst. Metal Finish., 1967, 45, 75 